\section{Authors}

BRIAN NIGHTENGALE, RPh, PhD, President, Good Neighbor Pharmacy, AmerisourceBergen, Chesterbrook, Pennsylvania.

AUTHOR CORRESPONDENCE: Brian Nightengale, RPh, PhD, President, Good Neighbor Pharmacy, AmerisourceBergen, 227 Washington St., Conshohocken, PA 19428. Tel.: 267.315.1445;

E-mail: BNightengale@amerisourcebergen.com.

\section{DISCLOSURES}

No funding supported the writing of this article. The author is an employee of AmerisourceBergen and leads its Good Neighbor Pharmacy program, which supports independent community pharmacy customers.

\section{REFERENCES}

1. National Community Pharmacists Association. 2019 NCPA Digest: changing the pharmacy payment model. 2019. Available at: http://www.ncpa.co/ pdf/digest/2019/2019-digest.pdf. Accessed April 21, 2020.

2. Fein A. The pharmacy industry's evolution: 2000 to 2010. Drug Channels Institute. September 13, 2011. Available at: https://www.drugchannels. net/2011/09/pharmacy-industrys-evolution-2000-to.html. Accessed April 21, 2020.

3. How the small, neighborhood pharmacy prevails. Triangle Business Journal. April 24, 2017. Available at: https://www.bizjournals.com/triangle/ news/2017/04/24/how-the-small-neighborhood-pharmacy-prevails.html. Accessed April 21, 2020.
4. Leading independent pharmacy buying groups pair up. Pharmaceutical Commerce. Updated March 20, 2017. Available at: https://pharmaceuticalcommerce.com/brand-marketing-communications/leading-independentpharmacy-buying-groups-pair. Accessed April 21, 2020.

5. Fein AJ. 2017 economic report on U.S. pharmacies and pharmacy benefit managers. Drug Channels Institute. February 2017. Available at: http:// drugchannelsinstitute.com/files/2017-PharmacyPBM-DCI-Overview.pdf. Accessed April 21, 2020.

6. IQVIA. Prescriptions and market share report. November 2019 Data/ Rolling 12-Month Rx Count. 2019

7. Fein A. New data: pharmacy owners' profits fall as industry competition rises. Drug Channels Institute. January 9, 2018. Available at: https://www. drugchannels.net/2018/01/new-data-pharmacy-owners-profits-fall.html. Accessed April 21, 2020.

8. Association of American Medical Colleges. New findings confirm predictions on physician shortage. April 23, 2019. Available at: https://www.aamc. org/news-insights/press-releases/new-findings-confirm-predictions-physician-shortage. Accessed April 21, 2020.

9. Moose J, Branham A. Pharmacists as influencers of patient adherence. Pharmacy Times. August 21, 2014. Available at: https://www.pharmacytimes.com/publications/directions-in-pharmacy/2014/august2014/pharmacists-as-influencers-of-patient-adherence-. Accessed April 21, 2020.

10. Krumme AA, Glynn RJ, Schneeweiss S, et al. Medication synchronization programs improve adherence to cardiovascular medications and health care use. Health Aff (Millwood). 2018;37(1):125-33. Available at: https://www. healthaffairs.org/doi/full/10.1377/hlthaff.2017.0881. Accessed April 21, 2020.

11. J.D. Power. Pharmacy customers slow to adopt digital offerings but satisfaction increases when they do, J.D. Power Finds. Press release. August 20, 2019. Available at: https://www.jdpower.com/business/press-releases/2019us-pharmacy-study. Accessed April 21, 2020.

\title{
A Sleeping Giant: Community Pharmacy's Potential Is Unrivaled
}

\author{
Troy Trygstad, PharmD, MBA, PhD
}

\section{Trygstad's Viewpoint}

$\mathrm{P}$ harmacies in the United States filled well over 4 billion prescriptions last year, with more than 3.7 billion of those filled at a community-based pharmacy. ${ }^{1}$ Up against nearly 900 million outpatient visits, 36 million hospitalizations, and 4.5 million home health service users, pharmacy continues to reign as the most

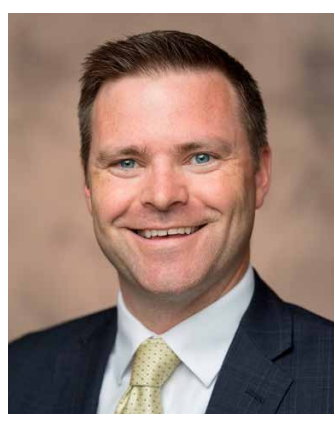

frequent potential service delivery touchpoint in the health care system. ${ }^{2-4}$

Largely untapped, community pharmacies can be the solution to our system's convenience care needs as on-demand walk-in facilities, as well as its chronic care needs as the most reliable, available, and cost-effective "eyes and ears" for the care team.

Not long ago, then Aetna Chief Executive Mark T. Bertolini described community-based pharmacy as the "new front door for health care in America." With consumer acceptance of retail J Manag Care Spec Pharm. 2020;26(6):705-08 Copyright $\odot 2020$, Academy of Managed Care Pharmacy. All rights reserved. sites of care becoming ever more acceptable, we may be on the verge of a significant market evolution. ${ }^{5}$ 


\section{If the Potential Is Never Realized, Pharmacy Becomes a Gigantic Missed Opportunity}

For the past 30 years, community pharmacy practice has endured a race to the lowest common denominator value proposition. Our expression of value has been reduced to a contest to produce the fastest, cheapest, and most interchangeable manner to dispense a medication, with de minimus attention to care delivery and patient outcomes. This is evident in the way purchasers contract with pharmacies based solely on product distribution and in our collective representation of quality measurement. Currently, the value proposition of pharmacies is projected on the rest of the system's purchasers and care team members via prescription fill rates and completion of comprehensive medication reviews, without regard to any therapeutic outcomes of interest whatsoever.

Lack of performance outcomes related to therapeutic outcomes hamstrings community pharmacies' collective expression of value. To improve Medicare star ratings related to volume of medication dispensed, the most effective means of value expression is not at all related to care delivery or pharmacy practice. Rather, 90-day fills are the favored intervention among data analysts and pharmacy benefit managers to improve adherence as measured by proportion of days covered, dwarfing care delivery-focused means of producing higher possession rates such as medication reconciliation, motivational interviewing, and tracking clinical markers and therapeutic goals. In addition, contemporary medication therapy management (MTM) approaches are measured on their ability to find problems rather than to solve problems or produce desired therapeutic outcomes.

\section{A \$100 Million MTM Industry Needs Evolution Toward a Much Larger Pharmacy Services Solution}

Care team members, as well as our government and employers, are screaming for value propositions that lower blood pressure, blood sugar, rates of depressive episodes, rates of asthma attacks, hospitalizations, and total cost of care and that provide for a better and more convenient patient experience close to home. So why can't we give it to them?

Leave it to pharmacists to undervalue and short sell themselves. If pharmacist services were a drug, would we cover it? We likely would, and we should, especially if pharmacies are willing to engage in value-based purchasing or outcomesbased reimbursement. Currently, we have a paltry $\$ 100$ million MTM industry in place to optimize medication use on $\$ 400$ billion in after-rebate pharmacy spend. That is $1 / 4000$ of drug spend allocated to optimizing the investment in medications to produce their intended clinical outcomes and achieve patient goals. True value will be realized by tying clinical, humanistic, and global economic outcomes to pharmacy services and dispensing reimbursement.

\section{Pharmacy Practice Is Not Expensive}

A mere $\$ 15$ billion devoted to optimizing medication use for Medicare enrollees is proportionally small in the macroeconomics of a $\$ 700$ billion program and would represent only $2 \%$ of the Medicare pie. If pharmacists were given the chance to associate payment with care delivery and accountability to therapeutic outcomes, it is entirely feasible to expect a $\$ 100$ billion pharmacy services industry to emerge. Indeed, analysts predict it could exceed $\$ 200$ billion. ${ }^{5}$

And, what if it were? $\$ 100$ billion on a $\$ 3.6$ trillion national health care expenditure is only $2.8 \%$ of the total national health care expenditure and that assumes that there are no cost savings or substitution effect associated with the pharmacist and pharmacy-provided health care services. ${ }^{6}$ This represents less than a third of our nation's after-rebate drug spend, which is also proportionally affordable at the macro level, representing only about $10 \%$ of our national expenditure-roughly the same as it was when the Social Security Amendment was signed in $1965 .{ }^{6}$ One of the greatest and most pernicious myths perpetuated emanates from the idea that prescription drugs drive the majority of health care spend and so too does pharmacy practice.

In reality, community pharmacy practice is an abhorrently low-cost purchase-to a fault as we continue to grind it down to nothing. We have driven community pharmacy practice to the brink of extinction in the name of saving money, when it currently represents less than $9 \%$ of our nation's drug spend and less than $1 \%$ of all health care spending. ${ }^{7}$ That is less than $1 \%$ to locate, staff, and operate 65,000 pharmacies. Drugs drive drug costs, not pharmacists or pharmacies.

\section{How Do We Get There? Bring on Accountable Pharmacy Organizations}

Mark McClellan's accountable care movement started at the turn of the century and became the vehicle of medical-side payment reform following the passage of the Affordable Care Act. ${ }^{8}$ It began with quality incentives, then shared savings, then downside risk, and now a slow but steady adoption of capitation arrangements between providers and purchasers of care delivery. Providers of care self-organize into contracting entities that are held financially accountable in aggregate for population-level metrics. Care delivery and payment is being forever changed.

To date, there has been no equivalent movement in pharmacy. Pharmacy providers remain essentially bystanders to accountable care, forced to express value through dispensing metrics rather than therapeutic and humanistic outcomes. What if pharmacy payments (i.e., services and dispensing fees) were based on $\mathrm{mmHg}$ and hemoglobin Alc and not fill rates? What if plans could contract with groupings of likeminded pharmacy providers and chain pharmacies based on readmission rates and rates of colonoscopy screening or 
successful referrals for treatment of opioid misuse or uncontrolled depression?

Accountable pharmacy organizations (APOs) may be the solution. Pharmacy practice can produce better patient outcomes and lower overall costs. ${ }^{9-13}$ We have simply never created the risk and reward environment in a meaningful way, at scale. If we follow the same path as our medical colleagues, managed care pharmacy and community pharmacy can thrive. Following McClellan et al.'s 2010 roadmap for medical providers, APOs would be legal entities that contract on behalf of pharmacy providers who agree to the provision of enhanced pharmacy services (beyond safe and accurate dispensing) and are willing to take risk on clinical, humanistic, and cost of care outcomes based on performance. ${ }^{8}$ Quality measurement starts with "the adoption of core 'starter set' of quality, efficiency, and patient-experience measures, making transition to advanced measures emphasizing health outcomes, functional status, and reductions in health risks." ${ }^{8}$ Risk can come in the form of a bonus payment, a penalty, or, in more advanced models, outcomes-based reimbursement in which even the pharmaceutical manufacturer may materially participate.

The expression of value would not be based on dispensing metrics, but rather the same metrics of interest for accountable care organizations (ACOs), thus aligning the ACO and APO movements in technology, workforce, and seeking value. Interoperable electronic standards-such as the HL7 Pharmacist Electronic Care Plan, which collects pharmacyprovided clinical and service delivery data, and use of NCPDP SCRIPT v2017071, which transmits vitals and lab findings (mandated by the Centers for Medicare \& Medicaid Services as of January 1, 2020)—already exist for the collection, reporting, and analysis necessary for accountable pharmacy services. ${ }^{14}$ These are not unicorns, they are being used at scale today. APOs would enable community pharmacies and their managed care pharmacy administrators and facilitators to adapt to a rapidly maturing medical plan-side outcomes marketplace that continues on without our participation.

Without Rapid Change, Community Pharmacy Practice Will Soon Become Irrelevant and then Nonexistent, and Managed Care Pharmacy's Influence May Follow

The death of community-based pharmacy practice represents an existential threat to managed care pharmacy. With every passing day, administrators outside of the world of pharmacy are beginning to realize that accountable care is practically impossible to deliver without robust medication optimization assets and programs. While plan-side managed care has been building up physician supports, care management, and other infrastructure to build up medication use supports designed to improve clinical, humanistic, and economic outcomes, we (all of us in pharmacy) have largely been tearing them down in the name of cost-cutting providers who are not driving increases in health care spend. Roughly 2 decades ago, the pharmacy benefit management industry sought to replace a business model built on generic use, with a model built on rebate maximization. Now it must transform itself again toward maximizing outcomes. Everyone else is doing it. And, if managed care pharmacy fails to materially participate in pharmacy practice and payment transformation, it will forever paint itself into a corner as the drug supply chain technocrats of the health care system, eliminating any future possibility of participating in the management of care delivery.

\section{Authors}

TROY TRYGSTAD, PharmD, MBA, PhD, Pharmacy and Provider Partnerships, Community Care of North Carolina, and CPESN USA, Raleigh, North Carolina.

AUTHOR CORRESPONDENCE: Troy Trygstad, PharmD, MBA, PhD, Executive Director, CPESN USA, 2300 Rexwoods Dr., Raleigh, NC 27607. E-mail: ttrygstad@n3cn.org.

\section{DISCLOSURES}

No funding was received for the writing of this commentary. The author has nothing to disclose.

\section{REFERENCES}

1. Kaiser Family Foundation. State health facts. Number of retail prescription drugs filled at pharmacies by payer. 2019. Available at: https://www.kff. org/health-costs/state-indicator/total-retail-rx-drugs/. Accessed April 24, 2020.

2. Rui P, Okeyode T. National ambulatory medical care survey: 2016 national summary tables. Available at: https://www.cdc.gov/nchs/data/ahcd/ namcs_summary/2016_namcs_web_tables.pdf. Accessed April 24, 2020.

3. American Hospital Association. Fast facts on U.S. hospitals, 2020. Available at: https://www.aha.org/statistics/fast-facts-us-hospitals. Accessed April 24, 2020.

4. Harris-Kojetin L, Sungupta M, Lendon JP, Rome V, Valverde R, Caffrey C. Long-term care providers and services users in the United States, 2015-2016 National Center for Health Statistics. Vital Health Stat 3(43). 2019. Available at: https://www.cdc.gov/nchs/data/series/sr_03/sr03_43-508.pdf. Accessed April 24, 2020.

5. Smith G, Lapsley H, Shellenbarger D. The new front door to the healthcare system is here. Oliver Wyman. March 2016. Available at: https://www. oliverwyman.com/our-expertise/insights/2016/mar/new-front-door-tohealthcare.html. Accessed April 24, 2020.

6. Centers for Medicare \& Medicaid Services. National health expenditure fact sheet. Updated March 24, 2020. Available at: https://www.cms.gov/ research-statistics-data-and-systems/statistics-trends-and-reports/nationalhealthexpenddata/nhe-fact-sheet.html. Accessed April 24, 2020.

7. Trygstad T. It's time to go to bat for community pharmacies. Pharmacy Times. July 15, 2019. Available at: https://www.pharmacytimes.com/publications/issue/2019/july2019/it-is-time-to-go-to-bat-for-community-pharmacies. Accessed April 24, 2020. 
8. McClellan M, McKethan A, Lewis J, Roski J, Fisher E. A national strategy to put accountable care into practice. Health Aff (Millwood). 2010;29(5):982-90. Available at: https://www.healthaffairs.org/doi/full/10.1377/hlthaff. 2010.0194. Accessed April 24, 2020.

9. Cranor CW, Bunting B, Christensen DB. The Asheville Project: long-term clinical and economic outcomes of a community pharmacy diabetes care program. J Am Pharm Assoc (Wash). 2003;43(2):173-84.

10. Anaya JP, Rivera JO, Lawson K, Garcia J, Luna Jr J, Ortiz M. Evaluation of pharmacist-managed diabetes mellitus under a collaborative drug therapy agreement. Am J Health Syst Pharm. 2008;65(19):1841-45.
11. Ni W, Colayco D, Hashimoto J, et al. Reduction of healthcare costs through a transitions-of-care program. Am J Health Syst Pharm. 2018;75(10):613-21.

12. Pellegrin KL, Krenk L, Jolson Oakes S, et al. Reductions in medicationrelated hospitalizations in older adults with medication management by hospital and community pharmacists: a quasi-experimental study. J Am Geriatr Soc. 2017;65(1):212-19.

13. Wright EA, Graham JH, Maeng D, et al. Reductions in 30-day readmission, mortality, and costs with inpatient-to-community pharmacist followup. J Am Pharm Assoc (2003). 2019;59(2):178-86.

14. Pharmacist eCare Plan Initiative. Available at: www.ecareplaninitiative.com. Accessed April 24, 2020.

\title{
Evolution of the Pharmacy Benefit Manager/Community Pharmacy Relationship: An Opportunity for Success
}

\author{
Patty Taddei-Allen, PharmD, MBA, BCACP, BCGP
}

\section{Taddei-Allen's Viewpoint}

$\mathrm{B}$ usiness commodities are any good or service that can be bought or sold based solely on price. These include typical commodities, such as agricultural products such as beans and rice and natural resources such as oil or gas. There is no difference in the brand, benefits, or distinguishing features when you buy rice from company A versus company B. Service product offerings can also become commodities when, in the eyes of the consumer, the service rendered is indistinguishable from others in terms of uniqueness or other attributes.

Unfortunately, the historical business model for community pharmacy has led to the commoditization of this important health care resource. The traditional community pharmacy business model of filling as many prescriptions as quickly and accurately as possible, and at lower and lower cost, has become unsustainable in our profession. If you take a survey of people's experiences with filling their prescriptions at one chain drug store versus another, or from one grocery store chain, big box store, or even an independent pharmacy, most people will respond that the service is pretty much the same. They may prefer a particular store because of the pharmacists and staff

J Manag Care Spec Pharm. 2020;26(6):708-10

Copyright $\odot 2020$, Academy of Managed Care Pharmacy. All rights reserved. who work there or because of the ease of being able to refill their prescriptions via an app, but the number one overwhelming reason why patients choose a drugstore is location. ${ }^{1}$

\section{Current Community Pharmacy Business Model}

Pharmacies enter contracts with pharmacy benefit managers (PBMs) to be part of a PBM network. The incentive for pharmacies to join networks, with predetermined rates for reimbursement for brand and generic products, as well as a dispensing fee, is to have access to a PBM's members who may go to their pharmacies to fill prescriptions. PBMs typically offer better rates for generics than brands in order to incentivize pharmacies to promote the use of generic products. Certain generics may also be managed by maximum allowable cost pricing, which limits the overall reimbursement for a particular medication based on the best cost available among different manufacturers, requiring the pharmacy to shop for the best-priced generic product from their wholesaler.

In 2012, the Centers for Medicare \& Medicaid Services released detailed data on pharmacy acquisition costs and pharmacy revenues, in essence making it possible to see how much profit pharmacies were making. An analysis of more than 3,200 drugs by Pembroke Consulting showed that the average gross profit per prescription was $\$ 7.46$. This is, however, a blended average gross profit, where about $5 \%$ of the drugs had 